\title{
Are Smart Card Ticketing Systems Profitable? Evidence from the City of Trondheim
}

\author{
Morten Welde \\ Norwegian University of Science and Technology
}

\begin{abstract}
Electronic ticketing in public transportation based on smart cards is gaining momentum worldwide. It is widely recognized that a smart card system can deliver benefits to both passengers and operators, but due to its complexity, implementation can come at a considerable cost. Therefore, it is likely that a commercial appraisal from the perspective of the public transportation operator alone would reveal that costs are higher than benefits and, hence, economic non-viability. This paper presents the experiences of the Norwegian city of Trondheim, which recently implemented a fully-interoperable electronic smart card system. A social cost-benefit analysis of the scheme is presented, focusing on net overall benefits for the passengers, the bus company, the local transportation authority, and the rest of society. The main conclusion of the paper is that the smart card ticketing system in Trondheim delivers a positive net present value. The paper demonstrates that economic evaluation of smart card ticketing schemes using the principles of social cost-benefit analysis is desirable and possible. Because commercial non-viability may represent constraints to the implementation of such schemes, the findings presented in this paper provide valuable information to those currently working on smart card ticketing strategies.
\end{abstract}




\section{Background}

Electronic ticketing in public transportation based on smart cards is gaining momentum worldwide. It is widely recognized that smart cards can deliver benefits to passengers and public transportation operators through time savings, increased travel convenience, more flexible ticketing, lower administrative costs, and better marketing information. The implementation of smart card systems is, however, a complex process that includes legal, economic, and technological issues. Implementation can thus come at a considerable cost. Therefore, it is likely that a commercial appraisal from the perspective of the public transportation operator alone would reveal costs higher than benefits and, hence, economic non-viability. Authorities and public transportation operators, therefore, often are reluctant to sanction large investments in such systems.

A striking example of transportation investments that may not generate sufficient revenues to justify private investment alone is public transportation investments. Public transportation often is subsidized to ensure that important services are provided even if they do not generate sufficient ticket revenues to justify their operations. Even in countries where the public transportation industry is completely deregulated, there is usually some kind of operator reimbursement for services such as certain rural routes, school travel, or free travel for older adults. Other arguments for subsidizing public transportation include the positive externalities generated by the service, the potential for user-scale economics (often referred to as the Mohring effect), and alleged public or merit good characteristics. This implies that, in reality, very few, if any, investments in public transportation are profitable from a purely commercial perspective. When deciding whether to implement smart card ticketing systems, the investment should be evaluated from a social perspective, following the principles of social cost-benefit analysis. Cost-benefit analysis (CBA) is a methodology based on the valuation of all relevant effects accruing from an investment or policy. Harberger (1971; cited in Winston 2006) described the principles of applied welfare economics through CBA as follows: benefits and costs to consumers should be calculated using consumer surplus; benefits and costs to producers should be calculated using producer surplus; and benefits and costs to each group should be added without regard to the individual(s) to whom they accrue. Thus, it is the change in consumer and/or producer surplus that determines the change in social surplus in a CBA. (For a comprehensive review of cost-benefit theory and methodology, see Boardman et al. 2006.) In other words, CBA is concerned with the welfare of society as a whole and not just a smaller part of it. That will be illustrated in this paper. 
This paper presents the experiences of the Norwegian city of Trondheim, which recently implemented a fully-interoperable electronic smart card system. A social cost-benefit analysis of the scheme is presented, focusing on net overall benefits for the passengers, the bus company, the local transportation authority, and the rest of society.

\section{Smart Card Ticketing in Trondheim}

The city of Trondheim (pop. 175,000), which is the third largest city in Norway, implemented electronic smart cards (the t:card) for its public transportation system in June 2008. It is a region-wide scheme in which customers can use one smart card based on one contract for buses, trams, and regional coaches operated by 10 public transportation operators in Trondheim and the 2 counties surrounding the city. The total population in the two counties, including Trondheim, is approximately 425,000 . Prior to this implementation, payment was based on a wide array of paper-based ticketing schemes. Customers still can pay with cash, but soon after implementation, smart card use accounted for approximately 70 percent of all payments; after more than three years of operation, approximately 90 percent of all trips currently are paid for using the t:card. This means that accommodating those customers who still pay their fares by cash is becoming more expensive, which raises the issue of transferring to full-scale electronic ticketing with no option to pay by cash. Customers using the t:card are offered discounts from 5-25 percent, depending on whether a pre-paid amount is deposited on the card or if it is linked to a bank account. In addition, monthly passes are offered, which gives frequent travelers significantly lowers fares than they would pay if purchasing single tickets. The single ticket cash fare in Trondheim is $\$ 5.30$, while the price of a monthly pass for the greater Trondheim area is $\$ 105$. (For more information, see the transit authority AtB's website: www.atb.no.)

In 2009, two thirds of the operating costs of public transportation in Trondheim were paid for by ticket revenues (approximately $\$ 35$ million). The remaining one third was covered by local authority subsidies. Ten years ago, the share of subsidies to costs was close to zero, but that share has increased due to fare reductions, increased operating costs and increased bus frequencies.

The public transportation system in Trondheim is based on 42 bus routes and 1 tram line. Trains, which are not currently part of the smart card system, carry pas- 
sengers to and from neighboring towns. Currently, the total number of bus trips per year is 21 million.

Until recently, bus services in Trondheim were provided by a direct contract with a publicly-owned local bus company, but now are based on gross subsidy tendering, where services are planned and managed by the transit authority AtB, a subsidiary of Sør-Trøndelag County, where Trondheim is located. With services now tendered, the quality of operations is expected to increase due to increased requirements to vehicles and services in the call for tenders. Beginning in fall 2011, all services are now provided by low-floor buses, which, fulfill the Euro 5 guidelines for emissions. New buses also have a rear access option for t:card holders. Although this option increases the risk of fraud, it is expected that it will contribute to reduced dwell times.

\section{Literature Review}

Smart cards are used for a number of different transportation applications, among which ticketing is the most widespread. However, despite being invented more than 30 years ago, the history of smart cards is littered with a number of spectacular and costly failures. Regardless, the last 15 years have seen a growing number of smart card schemes being launched, many of which are a result of the success of large-scale electronic ticketing schemes in Asia (Blythe 2004). This has led to an increased interest in investigations into the benefits and costs of smart card ticketing for public transportation.

In a report by the UK Department for Transport (DfT) and Detica (2009), the net present value (NPV) of a national smart ticketing infrastructure over a 10-year period was estimated at $\$ 36.8$ billion with full take-up. Even with a minimal rollout of smart cards, the NPV was estimated at $\$ 2.8$ billion, equivalent to a Benefit-Cost Ratio (BCR) of 1.8, which is close to the level considered as a high value for money (2.0). The DfT concluded that the installation of smart card infrastructure in UK public transportation has large one-off costs but relatively low operating costs. The benefits are large and come from factors such as modal shifts, cost savings, increased revenue, fraud reduction, better service, and improved access to and integration with other services. It is worth noting that the DfT report identified real scale economies in the implementation of smart card technology. Although some benefits could be gained from partial implementation, real payback is expected once a full national interoperable scheme is in place. 
The view of large potential benefits, however, was not supported by the Confederation of Passenger Transport. In a Local Transport Today article published on November 19, 2009, it was argued that the lack of smart card schemes in operation was not a result of market failure, but due to an unviable business case for public transportation operators and uncertain benefits for all parties involved. Fearnley and Johansen (2009) reached the same conclusion in a commercial appraisal of the Flexus system for public transportation in Oslo, which is struggling to implement an interoperable smart card system for buses, trams, and metro lines in Oslo and the neighboring county. The new system provided a negative NPV for the operator, and initial assumptions, so far, have turned out to be overly optimistic.

This is similar to the views of Iseki et al. (2008), who claimed that the benefits of smart card systems often are vague and that it is still unclear whether the benefits of smart cards outweigh the costs. The authors reviewed three case studies (and, according to the authors, the best studies available) of smart card systems in the U.S. and concluded that none of the three studies was based on complete and consistent applications of accepted cost/benefit methodologies. Their conclusions were that smart card systems hold great potential for providing extensive benefits in terms of speed, flexibility, and information, but at substantial time, effort, and monetary costs. The limitations of previous studies and the lack of general methodologies implied, however, that any study of current smart card schemes in operation would require substantial data collection and analysis. In this, Iseki et al. identified one of the most serious shortcomings of intelligent transport systems (ITS) and perhaps of smart card systems in particular: the consistent lack of comprehensive economic evaluations to properly appraise the costs and benefits of such schemes. As argued by Odeck and Welde (2010), when ITS projects are not evaluated according to the same methodologies as traditional transportation investments, many potential ITS projects may lose terrain relative to alternative solutions. In addition, ITS often represents new applications that are still in their early stages in many countries. Ascertaining their expected effects, therefore, often is difficult. This might make traditional evaluation methods such as costbenefit analysis (CBA) inappropriate. Although frameworks for CBA exist in most countries, these are not necessarily suitable for ITS evaluation. In particular, the limitations of traditional CBA for ITS evaluation are related to data issues, the time horizon, and the valuation of user benefits. Odeck and Welde nevertheless concluded that evaluating ITS projects using the principles of cost-benefit analysis is desirable and possible. Although there are costs and benefits associated with ITS that are difficult to monetize, most of the benefits and costs of ITS schemes, such 
as electronic payment systems, are measurable in monetary terms and, therefore, are suitable for CBA.

One of the very few economic appraisals of smart card technologies was presented by Cheung (2006), who analyzed the effects of the Dutch national smart card system. Although not necessarily providing benefits to each of the individual operators involved, the analysis indicated that the project has resulted in large cumulative benefits, with a BCR on the order of 0.2-0.5. The most important direct benefit for passengers was the amount of time spent purchasing tickets, while operators have benefited from reduced fraud and increased opportunities for more sophisticated price differentiation.

More recently, the ability of smart cards to generate new public transportation trips has been highlighted by research by Transport for London and consultant MIT. In a Local Transport Today article published on February 25, 2011, TfL's director of fares and ticketing said that, "Research suggested that $9 \%$ of all Oyster 'payas-you-go' journeys on the Underground were generated by the ease of using the Oystercard." The increased use of public transportation in London due to the Oyster card was estimated to generate some $\$ 83$ million per year. This has lead to calls for Oyster card systems to be implemented in neighboring Scotland to encourage bus and rail travel (Wilcox 2011).

\section{Framework for Evaluation}

In this paper, the evaluation of the smart card system in Trondheim is based on social cost-benefit analysis. Social CBA differs from commercial appraisal in that all costs and benefits associated with a particular scheme are included, regardless of to whom they accrue. This means that a scheme that involves direct revenues and turns out to be non-viable from a commercial perspective still may be desirable from a social perspective when all external benefits and costs are included.

The implementation of an interoperable smart card system in Trondheim was motivated by potential benefits for all parties involved and affected by public transportation in Trondheim: passengers, operators, local authorities, and the wider community. Table 1 outlines the expected impacts for all of the affected groups. 
Table 1. Benefits and Costs-Affected Groups

\begin{tabular}{|c|c|c|c|}
\hline Passengers & PT Operators & Local Authorities & Wider Community \\
\hline Time savings & Time savings & Improved statistics & Cost of taxation \\
\hline Reduced delays & Increased reliability & Project costs & Reduced emissions \\
\hline Less need to carry cash & Project and investment costs & & \\
\hline & Operating costs & & \\
\hline+ & $+/-$ & $-/+$ & $-/+$ \\
\hline
\end{tabular}

The introduction of smart cards in public transportation reduces the time spent boarding and paying, provided that payment is done when boarding. This constitutes a time saving for each passenger. Although this may be a small and potentially negligible time saving for the individual - normally not more than a few secondsit is important to note that the individual passenger will save time at every stop and for every foregoing passenger who previously would have paid by cash. Over the course of an average bus or tram journey, this could constitute a significant time saving for both the passengers and the operator(s). This is similar to the user-scale economies identified by Mohring (1972), where the presence of an additional user increases the likelihood of additional services being provided due to time savings and the resulting increased demand. This also is similar to benefits arising from measures to improve accessibility to passengers with special needs, often referred to as "universal design" (UD). The conventional thinking is that UD is for the few, i.e., the impaired, and given that they are few in numbers, UD projects generally will be unprofitable from a socioeconomic point of view because benefits will be low while investment costs will be high. However, a recent study has shown that UD projects may benefit all users of the facility, whether impaired or not, as the additional costs of implementation often are low; hence, their NPVs often are high and positive (Odeck et al. 2010).

Smart cards often also increase bus route reliability and reduce delays for passengers. Payment by cash can be a complex process, where the average time per passenger varies from a few seconds to more than a minute. This makes scheduling difficult. The introduction of smart cards normally reduces this pay time variability and, hence, contributes to both reduced delays and increased reliability.

Another benefit for passengers and operators is a reduced need for cash. Today, people are increasingly carrying no cash at all, and the percentage of transactions made by credit and debit cards is increasing annually. In 2009, there were 1.2 billion card transactions in Norway (up 10\% from 2008). This is equivalent to 246 transac- 
tions per person (Norges Bank 2010). Norges Bank, Norway's central bank, has estimated that cash settles only about 23 percent of transactions at the point of sale, representing 14-38 percent of the value of all sales. The ratio of the cash stock to GDP in Norway has fallen over the past decades and has fallen considerably faster in Norway than in the other Nordic countries (Gresvik and Haare 2008).

It is expected that smart cards, at least initially, increase operating costs for the operators involved. These, along with project and investment costs, which are shared with local authorities, represent the direct costs of implementing the smart card system. In addition, costs financed by the public sector through taxation should be multiplied by 1.20 , which is the standard marginal cost of public funds in Norway, reflecting the fact that distortive taxes lower welfare by more than they collect in revenue.

Finally, smart card systems normally provide local authorities with better public transportation statistics and ease the planning and scheduling of services. In addition, operators may benefit from additional information on customer trips, paving the way for loyalty schemes and a better understanding of customer needs and journey patterns (Davis 2002, in Blythe 2004). It is also not unreasonable to believe that, as smart cards reduce dwell time, local emissions could be reduced. This will benefit the wider community.

From the above, we notice that most of the envisaged effects can be measured in monetary terms, and an economic assessment can be done. In CBA, the relevant investment criteria are the net present value (NPV) and the benefit cost ratio (BCR).

The NPV can be expressed as follows:

$$
N P V=I_{0}+\sum_{t=0}^{n} \frac{B_{t}-C_{t}}{(1+r)^{t}}
$$

Here, $B$ and $C$ represent benefits and costs, $r$ represents the discount rate, and $t$ represents the time period. The NPV determines the absolute economic merit of a project. If its value is greater than zero, it means that the project generates benefits that are greater than its cost and is therefore profitable from an economic point view.

The BCR is a value for money measurement and is different from the NPV. It is defined as the ratio of the net benefits of a project to its costs. Formally, the BCR is written as: 


$$
B C R=\frac{N P V}{C}
$$

The $B C R$ has a simple interpretation, making it useful for policy makers to judge the worthiness of projects in terms of returns per euro invested. If the ratio of NPV to the total costs of carrying out the project $(C)$ is, for example, 0.2 , it means that the returns are 20 percent, or a 20 -cent profit for every dollar invested in the project.

In practice, we use the NPV to determine whether a project is profitable from an economic point of view. If the aim is to rank ITS projects among themselves or against other projects, then the BCR should be used, because it shows which projects give the greatest returns per dollar invested.

\section{Data and Methodology}

\section{Data}

The data for the analysis were collected in cooperation with AtB, the body responsible for Trondheim's public transportation system. Stensrud and Kuipers (2008) provided a comprehensive overview of all costs associated with the smart card system. Although it was implemented in 2008, the process leading up to implementation was arduous and prolonged. The planning started in the early 1990s, but because implementation turned out to be more complex than was first assumed, it was postponed several times. The process even resulted in a court case with the equipment supplier, which ended in a settlement in 2007. After the settlement, the project was restarted and reorganized. Therefore, as the project contents and organization have been so different, the project can be split into two phases: before and after the court settlement in 2007. In this paper, we use the costs after 2007 as the basis for the analysis. The analysis covers only the city of Trondheim and not those neighboring regions where the t:card also can be used.

Time savings usually constitute the largest share of estimated benefits of transportation projects, and the estimation of time saved per passenger, therefore, requires careful calculation. The estimated time saving of 6.8 seconds, as shown in Table 2, for each boarding passenger using a smart card is based on registrations performed by students at the Norwegian University of Science and Technology during the spring of 2009. The means are based on a sample of 900 observations. Unfortunately, this was done almost a year after implementation, and we cannot rule out the possibility that those still opting for cash payment at this stage represent the slower payers. The time savings, thus, may be underestimated. As Table 2 
shows, even smart card transactions take time, but cash is more time-consuming and, above all, involves more variability in time spent per passenger, which makes scheduling more difficult.

\section{Table 2. Time in Seconds Spent on Cash Payment vs. Smart Card Payment}

\begin{tabular}{lcc}
\hline & $\begin{array}{c}\text { Cash } \\
\text { Transactions }\end{array}$ & $\begin{array}{c}\text { Smart Card } \\
\text { Transactions }\end{array}$ \\
\hline No. of cases & 436 & 466 \\
Mean & 8.3 & 1.5 \\
St. dev. & 6.5 & 1.8 \\
Minimum & 2 & 1 \\
Maximum & 47 & 18 \\
\hline
\end{tabular}

The analysis is based on measured data after 12-24 months of operation. In addition to time savings, the data are composed of investment and operating costs, reinvestment costs, project costs, bus trips, t:card shares, load factors, and standard national values for the value of time and discount rates. The appraisal period is 10 years. This is considerably shorter than what is used for traditional transportation expenditures, which are appraised over a 25 -year period. A 10-year appraisal period reflects the uncertainty associated with technology investment and ensures a conservative approach to the analysis. The main parameters used in the estimation are listed in Table 3.

\section{Table 3. Parameters Used in the Estimation}

\begin{tabular}{ll}
\hline Parameter & Value* $^{*}$ \\
\hline Investment costs & $\$ 2,400,000$ \\
Operating costs per year & $\$ 900,000$ \\
Annual service and maintenance costs & $\$ 200,000$ \\
Reinvestment costs (every three years) & $\$ 1,400,000$ \\
Project costs (before implementation) & $\$ 1,400,000$ \\
Total number of bus trips per year & $17,300,000$ \\
Share of trips performed with the t:card & $70 \%$ in $2008,80 \%$ in $2009,90 \%$ thereafter \\
Annual increase in the number of bus trips & $2.5 \%$ \\
Average time saving per t:card transaction & 6.8 seconds \\
Average load factor & 20 \\
Time value for bus passengers & $12.5 /$ hour \\
Time value for bus company & $65.9 / \mathrm{hour}$ \\
Discount rate & $4.5 \%$ \\
Appraisal period & 10 years \\
Marginal cost of public funds & $20 \%$ \\
\hline
\end{tabular}

*U.S dollars-values based on exchange rate of August 15, 2011 
The Norwegian framework for CBA of transport investment provides guidelines for project appraisal, including standard values of time, marginal cost of public funds, and the discount rate.

\section{Methodology}

The average time saving per passenger is estimated to be 6.8 seconds for each time a boarding passenger uses a smart card instead of paying by cash. Notice that this does not mean that each smart card transaction represents a time saving. The previous paper-based ticketing arrangements also included monthly passes, which holders would simply display to the bus driver. This proportion of users would not generate time savings when switching to the t:card.

This means that the total gross time savings $t$ per year, measured in hours for passengers using smart cards, can be expressed as follows:

$$
T_{t_{\text {:card }}}=\frac{P_{\text {t:card }} \times t k_{\mathrm{sec}}}{3600}
$$

where $P_{t: c a r d}$ is the total number of passengers using smart cards per year, and $t k_{\text {sec }}$ denotes the average time savings per smart card transaction.

The net annual time savings for all passengers is expressed as:

$$
T_{\text {tot }_{t}}=\left(T_{\text {t:card }_{t}}+\left(T_{\text {t:card }_{t}} \times B P\right) \times(1-m)\right)
$$

Here, the time saving for smart card users is adjusted for $m$, the proportion of users with monthly passes in the last year before smart card implementation. In addition, the equation includes time savings for passengers already on the bus (the average load factor), $B P$. These passengers also will save time at each bus stop whenever a boarding passenger uses a smart card.

The annual value of time savings can then easily expressed as:

$$
B_{t}=\left(T_{\text {tot }_{t}} \times w_{p}\right)+\left(T_{\text {t:card }_{t}} \times w_{b}\right)
$$

Here, $w_{p}$ and $w_{b}$ express the value of travel time savings for bus passengers and the bus company, respectively.

By including investment costs and operating costs and inserting $B_{t}$ into Equation (1), we are able to calculate the NPV of the smart card ticketing system in Trondheim. 


\section{Results}

Based on the data and methodology presented above, a cost-benefit analysis was performed. The results are presented in Table 4.

\section{Table 4. Cost-Benefit Analysis of the Smart Card System in Trondheim}

\begin{tabular}{lccc}
\hline & NPV Costs* & NPV Benefits & NPV \\
\hline Investment costs & $(\$ 2,400,000)$ & & \\
Project costs & $(\$ 1,400,000)$ & & \\
Operating and reinvestment costs & $(\$ 12,000,000)$ & & \\
Marginal cost of public funds & $(\$ 800,000)$ & & \\
Time savings of bus passengers & & $32,800,000$ & \\
Time savings of bus company & & $16,300,000$ & \\
\hline NPV & $\mathbf{( 1 6 , 6 0 0 , 0 0 0})$ & $\mathbf{4 9 , 1 0 0 , 0 0 0}$ & $\mathbf{3 2 , 5 0 0 , 0 0 0}$ \\
BCR & & & $\mathbf{1 . 9 6}$ \\
\hline
\end{tabular}

The smart card ticketing system in Trondheim is profitable from a socioeconomic point of view, with an NPV of $\$ 32.5$ million. This equals a BCR of 1.96, meaning that $\$ 1$ spent on the t:card system generates benefits of $\$ 2.96$. This is also substantially more than what is usually provided through traditional transportation expenditure, which, in the Norwegian case, may struggle to deliver a positive NPV at all. This analysis differs from one that a transit agency or a public transportation operator typically might carry out in two respects, in that it includes the costs of funds financed by taxation and, most importantly, it includes the values of travel time savings for both bus passengers and the bus company.

The implementation of smart card ticketing is a complex process, involving a number of actors and requiring readjustments for both operators and passengers. It often takes time before all challenges are overcome and before all benefits can be realized. In our opinion, the long-term objective should be to abolish cash payment completely. This will increase the social surplus further through the elimination of the need to handle cash-an expensive operation. In some countries, abolishing cash payment is said to be unrealistic, as certain income groups do not qualify for credit card payments or pre-paid card payments. That may be true for activities such as grocery shopping, but public transportation ticketing systems, which are based on small amounts, usually do not rely fully on customers qualifying for credit or who have their travel card accounts linked to a bank account. Both the t:card in Trondheim and the Oyster card in London allow users to store a pre-paid cash amount on the card regardless of creditworthiness. 
In time, it should also be a realistic objective to reduce the costs of operating the system. The first years of a new ticketing system often have a high number of customer inquiries, but as users become familiar with the system and take advantage of more efficient ways to manage their contracts, savings could be realized. It is also worth noting that conservative estimates were used throughout the analysis. It is likely that the NPV of Trondheim's smart card system is higher than that estimated above.

There are a number of benefits that are not monetized and included in the analysis. One such benefit is the above-mentioned reduced need for cash. For bus drivers, large amounts of cash pose a security risk. During the last five years, there have been several robberies and attempted robberies on buses in Trondheim, and the union representing the drivers has suggested a complete removal of all cash on board the buses. In Sweden, work to remove cash from buses is in progress in several cities (Rathe 2008), and the t:card could therefore be a step in the direction of cashless public transportation in Trondheim.

Another non-monetized benefit is the improved quality of public transportation statistics. Accurate travel information is important for transportation research, policy analysis, and planning. Previous paper-based systems failed to provide planners with necessary information. Statistics were incomplete and consisted of a limited set of information needed for analysis and planning. Previously, the bus company in Trondheim, which was responsible for collecting the data, even failed to provide information on the development in the number of bus passengers from one year to the next. The introduction of smart cards has improved this situation, and now detailed statistics on the number of trips per bus service, including time of day and day of week, are available. It is expected that this information could be used to improve the quality of public transportation in Trondheim.

Trondheim's smart card system generates substantial time savings for both passengers and operators. Take a 5-kilometer bus service with 10 stops as an example. At an average speed of 15 kilometers per hour, the trip will take 19 minutes, $48 \mathrm{sec}-$ onds. If, at each stop, two of the passengers boarding are previous cash payers, this will generate a total time savings of two minutes. Depending on where passengers board along the route, this could constitute a time savings of up to 10 percent. It is not unreasonable to expect that this time savings could increase the demand for public transportation. Rødseth and Bang (2006) used a travel time elasticity of -0.26 , whereas Balcombe et al. (2004) reported long-run travel time elasticities between -0.38 and -0.69 . This means that a 10 percent reduction in travel time along a bus route could generate passenger growth on the order of 3-7 percent. 
Introducing smart cards and increasing the efficiency of ticketing, hence, could be efficient tools in increasing the demand for public transportation and promoting a modal shift away from private cars.

\section{Conclusions}

In this paper, we have demonstrated that the smart card ticketing system in Trondheim delivers a positive net present value. For bus passengers, the main benefit lies in time savings during boarding and reduced dwell time. Although these represent only a small time saving for the individual, all passengers already on the bus will save time at every stop when passengers pay using smart cards, so the total time savings due to the t:card could be considerable over the course of a bus trip. This is an example of user-scale economics. Further passenger benefits include increased timetable reliability and a reduced need for cash. The bus company benefits from reduced delays and increased reliability because of the shorter time spent at bus stops. This could allow the bus company to reduce the number of buses needed or increase the service level to passengers.

This paper has demonstrated that economic evaluation of smart card ticketing schemes using the principles of social cost-benefit analysis is desirable and possible. Even if all effects are not monetized and included in the analysis, the main costs and benefits are, and because the non-included non-monetized effects mostly would have increased the net benefits of the scheme, we consider the analysis to be robust and, if anything, erring on the pessimistic side. Because commercial non-viability often constrains the implementation of smart card schemes, these findings provide valuable information to those currently working on smart card ticketing strategies.

\section{References}

Balcombe, R., R. Mackett, N. Paulley, J. Preston, J. Shires, H. Titheridge, M. Wardman, and P. White. 2004. The demand for public transport: A practical guide. Transport Research Laboratory, Report No. TRL 593.

Blythe, P. T. 2004. Improving public transport ticketing through smart cards. Municipal Engineer (1) 157: 47-54.

Boardman, A. E., D. H. Greenberg, A. R. Vining, and D. L. Weimer. 2006. Cost-Benefit Analysis. Concepts and Practice. New Jersey: Pearson Prentice Hall. 
Cheung, F. 2006. Implementation of nationwide public transport smart card in the Netherlands. Transportation Research Record 1971: 127-132.

Department for Transport. 2009. The benefits and costs of a national smart card ticketing infrastructure. Department for Transport and Detica Report. HMSO, July 2009.

Fearnley, N., and K. W. Johansen. 2009. Lønnsomhetsvurderinger av nytt billetteringssystem i Oslo [Evaluation of business case for new electronic ticketing system in Oslo]. Institute of Transport Economics, Report No. 1007/2009.

Gresvik, O., and H. Haare. 2008. Payment habits at point of sale. Staff memo no. 6, 2008. http://www.norges-bank.no/ (accessed: February 12, 2011).

Iseki, H., A. Demisch, B. D. Taylor, and A. C. Yoh. 2008. Evaluating the costs and benefits of transit smart cards. California PATH Research Report UCB-ITSPRR-2008-14. University of California, Berkeley.

Mohring, H. 1972. Optimization and scale economies in urban bus transportation. American Economic Review 62 (4): 591-604.

Norges Bank. 2010. Årsrapport om betalingssystem 2009 [Annual report on payment systems 2009]. http://www.norges-bank.no/ (accessed: February 12, 2011).

Odeck, J., T. Hagen, and N. Fearnley. 2010. Economic appraisal of universal design in transport: Experiences from Norway. Research in Transportation Economics 29 (1): 304-311.

Odeck, J., and M. Welde. 2010. Economic evaluation of ITS-strategies-The case of the Oslo toll cordon. IET Intelligent Transport Systems 4 (3): 221-228.

Rathe, T. 2008. Kommer i Norge, om ikke så brått [Coming to Norway, but slowly]. Transportforum 6/7: 18-20.

Rødseth, J., and B. Bang. 2006. ITS i kollektivtrafikken. Statens vegvesens etatsprosjekt "ITS på veg" [ITS in public transportation]. SINTEF Teknologi og samfunn, STF50 A05223.

Stensrud, K. H., and K. Kuipers. 2008. Anbefalt organisering og kostnadsestimater for drift av elektronisk billettering i Trøndelag (EBIT) [Recommended organization and cost estimates for electronic ticketing in Trøndelag]. Capgemini Norge AS. 
Wilcox, T. 2011. Calls for Oyster Card in Scotland to encourage bus and rail travel. http://news.coachbroker.co.uk/calls-for-oyster-card-in-scotland-to-encourage-bus-and-rail-travel-283400/ (accessed: August 15, 2011)

Winston, C., 2006. Government Failure versus Market Failure. Washington D.C.: Brookings Institution Press.

\section{About the Author}

MORTEN WeLDE (morten.welde@vegvesen.no) is with the Norwegian Public Roads Administration in Oslo and the Norwegian University of Science and Technology in Trondheim. 